\title{
Monitoring viral RNA in infected cells with LNA flow-FISH
}

\author{
KELLY L. ROBERTSON, ${ }^{1}$ ANNE BROOKS VERHOEVEN, ${ }^{2}$ DZUNG C. THACH, ${ }^{3}$ and EDDIE L. CHANG ${ }^{1}$ \\ ${ }^{1}$ Laboratory for Biosensors and Biomaterials, Code 6910, Center for Bio/Molecular Science and Engineering, Naval Research Laboratory, \\ Washington, District of Columbia 20375, USA \\ ${ }^{2}$ Department of Molecular and Microbiology, George Mason University, Manassas, Virginia 20110, USA \\ ${ }^{3}$ Laboratory of Infectious Diseases, Department of Health and Human Services, National Institute of Allergies and Infectious Diseases, National \\ Institutes of Health, Bethesda, Maryland 20892, USA
}

\begin{abstract}
We previously showed the feasibility of using locked nucleic acid (LNA) for flow cytometric-fluorescence in situ hybridization (LNA flow-FISH) detection of a target cellular mRNA. Here we demonstrate how the method can be used to monitor viral RNA in infected cells. We compared the results of the LNA flow-FISH with other methods of quantifying virus replication, including the use of an enhanced green fluorescent protein (EGFP) viral construct and quantitative reverse-transcription polymerase chain reaction. We found that an LNA probe complementary to Sindbis virus RNA is able to track the increase in viral RNA over time in early infection. In addition, this method is comparable to the EGFP construct in sensitivity, with both peaking around $3 \mathrm{~h}$ and at the same level of infected cells. Finally, we observed that the LNA flow-FISH method responds to the decrease in levels of viral RNA caused by antiviral medication. This technique represents a straightforward way to monitor viral infection in cells and is easily applicable to any virus.
\end{abstract}

Keywords: LNA; RNA; flow cytometry; fluorescence in situ hybridization; viral nucleic acids

\section{INTRODUCTION}

The ability to detect and study viruses is of great importance for biomedical and biotechnological applications, and for detection of biowarfare agents. Because viruses cause many human diseases, it is critical that we collect valuable information on viral nucleic acids, life cycles, and infection characteristics. Methods that allow the study of these characteristics are valuable for advancing the development of vaccines and therapies to prevent and treat viral infections.

Currently, there are many methods used for the detection and study of viruses, all of which have particular benefits and limitations. Antibodies are widely used to detect viruses and viral proteins (Cho et al. 1996; Bentzen et al. 2005; Dawson 2007; Rabenau et al. 2007; Polage and Petti 2009), but due to their specificity, must be produced and calibrated for every target and are highly vulnerable to viral mutations. Quantitative reverse-transcription polymerase chain reaction (qRT-PCR), microarrays, and enzymelinked immunosorbent assays (ELISAs) are other widely

Reprint requests to: Eddie L. Chang, Laboratory for Biosensors and Biomaterials, Code 6910, Center for Bio/Molecular Science and Engineering, Naval Research Laboratory, 4555 Overlook Avenue SW, Washington, DC 20375, USA; e-mail: eddie.chang@nrl.navy.mil; fax: (202) 767-9511.

Article published online ahead of print. Article and publication date are at http://www.rnajournal.org/cgi/doi/10.1261/rna.2016410. used methods to detect and quantify viruses (Steininger et al. 2002; Wang et al. 2002; Fox 2007; Leski et al. 2009; Mosleh et al. 2009). While these methods are highly sensitive, they each have shortcomings. Because cells must be lysed prior to these assays, neither is able to provide information about viral viability, infected cell phenotypes, or the relationship between cells and cytopathic phenotypes. In addition, since the signal is averaged over the number of input cells that are lysed, one cannot associate a signal with an individual cell or determine the distribution of infection in cellular populations. Traditional plaque assays, while widely used, are time consuming and rely on cytopathic effects, which are not produced by all viruses or may take long periods of time to occur (Los 2006). In addition, plaque assays are unable to detect noninfectious viruses, which decreases the sensitivity of the assay. Other methods involve the genetic recombination of the virus to express a fluorescent protein upon transcription of the viral genome, which is then translated by the host cell (Thach and Stenger 2003; Sanz et al. 2007; Delehanty et al. 2008). While the signal corresponds with the amount of virus present in individual cells, this technique involves a large initial investment of labor for each virus of interest and changes the nature and pathological phenotypes of the virus.

Fluorescence in situ hybridization (FISH) combined with flow cytometry (flow-FISH) has the potential to overcome 
many of the issues with traditional virus detection assays. Flow-FISH has been used for telomere length determination, the analysis of microorganisms, and the detection of messenger RNA (mRNA) and viral RNA (Bauman et al. 1990; Bayer and Bauman 1990; Belloc et al. 1993; Belloc and Durrieu 1994; Stowe et al. 1998; Baerlocher et al. 2002). In flow-FISH each cell is treated as an independent observation, thereby enabling the detection of cells containing specific nucleic acid sequences and the quantification of the number of infected cells in a population. Flow-FISH also allows for multiplexed detection of viral nucleic acids, as well as host nucleic acids of interest. This enables researchers to positively verify the presence of virus and correlate that information directly to the changes in host genes in each individual cell. In addition, flow cytometry allows the analysis of a large number of cells and the detection of rare cells in mixed solutions.

While FISH and flow-FISH have been used previously to detect and study viruses (Lizard et al. 1993; Borzì et al. 1996; Crouch et al. 1997; Just et al. 1998; Stowe et al. 1998; Mulrooney and Michalak 2003; Vermeulen et al. 2007), these techniques can be time consuming, with limitations in sensitivity and resolution. As we have discussed elsewhere (Robertson and Thach 2009) the use of high affinity nucleic acid analogs has been shown to increase the sensitivity and specificity of the technique (Taneja 1998; Thomsen et al. 2005). While the nucleic acid analog, peptide nucleic acid (PNA), has been used for the detection of viral nucleic acids in the past (Just et al. 1998), locked nucleic acid (LNA) binds to complementary DNA and RNA with higher affinity than analogous PNA and is superior to PNA for many applications (Braasch and Corey 2001; Elayadi et al. 2002; Robertson and Thach 2009). In LNA, the ribose sugar is constrained by a methylene bridge between 2 '-oxygen and $4{ }^{\prime}$-carbon, resulting in an N-type (3-endo) conformation (Obika et al. 1997; Koshkin et al. 1998) that dramatically increases the melting temperature $\left(T_{\mathrm{m}}\right)$ of the double-stranded oligomer (Koshkin et al. 1998; Braasch and Corey 2001). LNA-modified oligonucleotide probes have been shown to be superior to DNA probes in many areas, including their sensitivity and specificity for FISH (Silahtaroglu et al. 2003, 2004; Thomsen et al. 2005; Kubota et al. 2006).

We have recently reported on the development of an LNAbased flow-FISH method for mRNA detection (Robertson and Thach 2009), and here we use LNA flow-FISH for the quantitative and sensitive detection of intracellular RNA in a viral-infection model using Sindbis virus (SV). SV is the prototype virus for the genus $\alpha$ virus and the family togaviridae. SV is a positive, single-stranded RNA virus whose genomic RNA serves as the mRNA for translation of the viral proteins, as well as the template for synthesis of the complementary minus-strand (Kuhn 2007). The genome can be divided up into two regions, the nonstructural protein (NSP) region and the subgenomic structural pro- tein (SP) region (Scheme 1). The SV SPs are translated from the subgenomic RNA early ( $2-3 \mathrm{~h}$ post-infection) in the replication cycle, probably as soon as the subgenomic mRNA is formed.

We build upon our previous LNA flow-FISH optimization experience and adapt the method for in vitro monitoring of a viral infection. To our knowledge, this is the first time that the increase in viral RNA has been followed over time with flow-FISH. We infect cells with SV virus and perform flow-FISH at various early time points during infection. In addition, we compare and confirm our results with two other methods for viral detection (EGFP viral expression and qRT-PCR) and test the LNA flow-FISH method for use in antiviral drug research.

\section{RESULTS AND DISCUSSION}

\section{Specificity of SV LNA probe}

For SV RNA detection, a complementary LNA probe was designed to hybridize to the structural protein region of the viral RNA genome (Scheme 1). This region encodes for the structural proteins and is transcribed at a higher rate than that of the nonstructural region (Kuhn 2007). The signal from the SV LNA probe was tested for specific binding in BHK cells in the absence of infection (Fig. 1A; "No Infection") and at various times post-infection (Fig. 1B shows 4-h post-infection only). In the absence of infection, the SV LNA does not exhibit any nonspecific binding and, in fact, gives a slightly lower signal than the nonspecific LNA (Fig. 1A). At 4-h post-infection, the SV LNA probe shows a signal that correlates with increased SV RNA from virus replication (Fig. 1B). From the flow signals, one can also see that the SV LNA is detecting only the infected cells, while the uninfected cells (or infected cells that contain little or no quantity of SV RNA) are giving a signal in a region that corresponds with the nonspecific LNA signal. Overall, the LNA probe designed for SV RNA was found to be able to easily distinguish the proportion of cells that are infected and undergoing viral replication from the population that is either not infected or not in an actively replicating state (Fig. 1A,B).

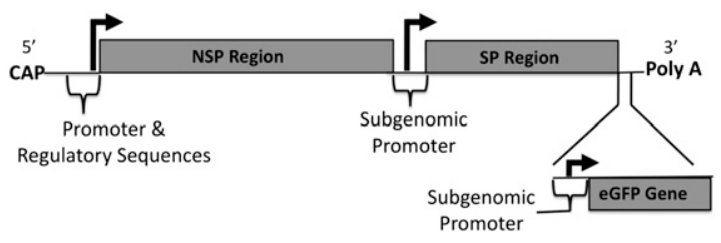

SCHEME 1. Schematic of the Sindbis virus genome outlining the structural and nonstructural protein regions (data adapted from Cheng et al. 1996). The SV LNA is complementary to the structural protein region. 

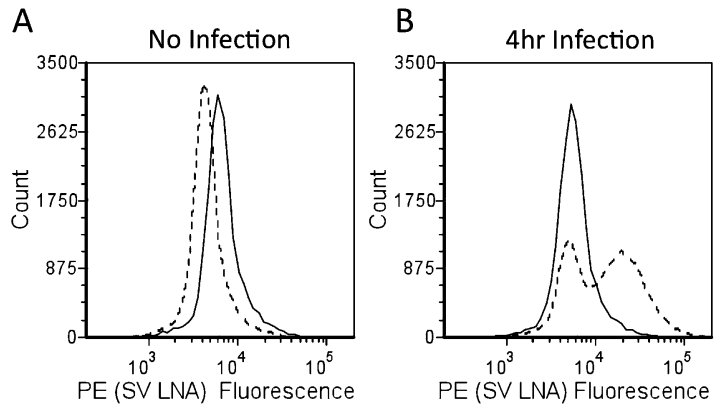

FIGURE 1. Specificity of SV LNA probe. (A) No infection; (B) 4-h infection; nonspecific LNA (solid line), SV LNA (dotted line).

\section{Monitoring viral infections}

In the SV construct used here (Scheme 1) a gene encoding enhanced green-fluorescent protein (EGFP) was placed under control of a promoter that is identical to the promoter of the viral structural proteins. Therefore, during Sindbis virus replication, infected cells are expected to produce intracellular EGFP at levels proportional to the viral structural proteins (Thach and Stenger 2003; Delehanty et al. 2008). This feature was used to make a direct comparison of the EGFP protein detection with the SV RNA LNA detection.

Figure 2, A and B, compare the flow cytometry histograms for the LNA flow-FISH and EGFP techniques at points corresponding to no infection, 1.5, 2, 3, and $8 \mathrm{~h}$ post-infection. The EGFP starts showing a shift in signal at $1.5 \mathrm{~h}$, while the LNA flow-FISH can detect the SV RNA at $2 \mathrm{~h}$. This difference is quantitatively displayed in Figure 3, left panel, which shows the number of positive cells for SV at each time point $(0,1.5,2,2.5,3,4,6$, and $8 \mathrm{~h})$. The EGFP signal increases at a slightly quicker rate than the signal from SV LNA, but both plateau to the same level after $3 \mathrm{~h}$. The same peak-signal levels show that the LNA-flow-FISH method is comparable to the EGFP construct in sensitivity when measured by flow cytometry. The slight differences in dynamics may due to the likelihood that more SV protein is expressed than the RNA template. The advantage of the LNA flow-FISH is that by simply changing the LNA probe, any virus can theoretically be detected, whereas in the case of EGFP, a new viral construct would be necessary for every virus or mutant.

\section{Quantitative RT-PCR}

Quantitative RT-PCR was used to confirm the LNA flowFISH results. A standard curve was produced using viral RNA purified from SV supernatants. The standard curve was used to calculate the SV RNA expression at each time point relative to the expression at the no infection time point (Fig. 3, right panel). Unsurprisingly, qRT-PCR could detect SV RNA in infected cells at the earliest time point of infection (45-min infection or 0-h Infection). Although the
qRT-PCR and the LNA flow FISH method began detecting SV RNA at different times, the increases in the SV RNA expression level detected over time are very similar (Fig. 3, both panels).

While qRT-PCR is a highly sensitive technique for viral detection in cell lysates, it provides no information regarding viral viability, individual cell phenotype, infection distribution in cellular populations, or the relationship between the cells and pathological features. In addition, the fast and simple flow-FISH method is inexpensive compared with the cost of primers, probes, and enzymes for qRTPCR. The LNA flow-FISH method also allows the simultaneous examination of viral nucleic acids as well as host nucleic acids and/or proteins through multiplexing, providing valuable information about host cell response to infection.

\section{Tracking the effects of antiviral drugs}

Both LNA-flow-FISH and EGFP fluorescence measurements were used for tracking the effects of the antiviral medication Ribavirin (Rbv). Rbv is a nucleoside analog that inhibits the replication of many DNA and RNA viruses including Sindbis (Malinoski and Stollar 1981). To test the ability of the flow-FISH method to monitor the action of antiviral drugs, samples infected with SV were analyzed with and without Rbv. After a 6-h incubation with Rbv, both the flow-FISH and EGFP results showed a reduction in viral replication and viral expression, respectively (Fig. 4). The controls (no infection, $0 \mathrm{~h}$ infection [ $45 \mathrm{~min}$ virus incubation], and $6 \mathrm{~h}$ no infection $+\mathrm{Rbv}$ ) all show no change in SV RNA.

These results reconfirm that Rbv decreases the ability of the virus to replicate and shows the utility of the LNA flowFISH method for monitoring SV RNA in the presence of antivirals. While the mechanism of $\mathrm{Rbv}$ is known, the additional information provided by the LNA flow-FISH method such as cell viability, cell morphology, and infection distribution, may be able to give insight into the mechanism of other antiviral medications.
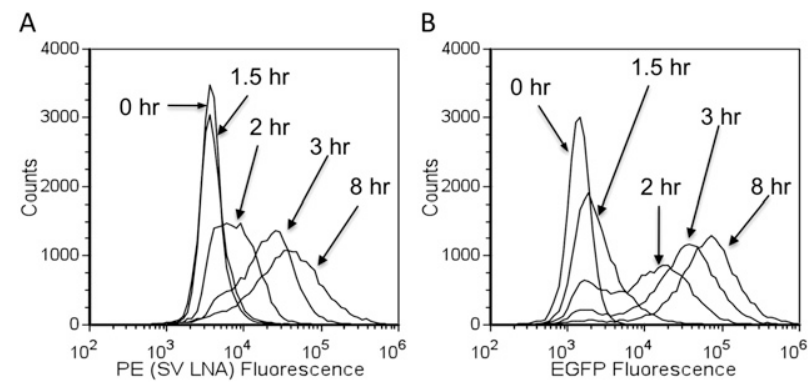

FIGURE 2. SV LNA flow-FISH versus EGFP detection of Sindbis RNA over time. Histograms showing representative flow cytometry data for specific time points for $(A)$ SV LNA and $(B)$ EGFP. 

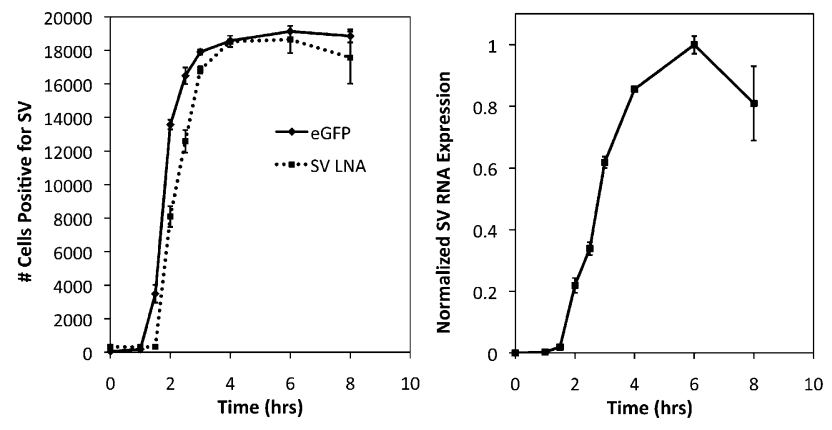

FIGURE 3. (Left panel) Number of cells positive for SV over time as detected by SV LNA (squares) and EGFP (circles). (Right panel) Normalized qRT-PCR data showing the relative amount of SV RNA at each time. The qRT-PCR data was normalized relative to the no infection expression level. Each point shown is the mean value of three replicates; error bars indicate standard error.

\section{CONCLUSION}

In conclusion, we have used LNA-modified oligonucleotide probes for the specific and sensitive detection of viral RNA, and show that LNA flow-FISH can be used to follow the initial stages of a viral infection. We compared the LNA flow-FISH method with an EGFP-SV construct and qRTPCR and found similar results. In addition, we were able to follow the viral infection over time and study the action of antiviral medication.

The flow-FISH method described here utilizes one LNA probe and one fluorophore in contrast to many other flow-FISH methods, which need two or more oligonucleotide probes for detection (Borzì et al. 1996; Crouch et al. 1997; Just et al. 1998; Stowe et al. 1998; Narimatsu and Patterson 2005). With small changes such as the addition of a second biotin at the $3^{\prime}$ end of the probe or the addition of a second or third LNA probe complementary to the same RNA, the fluorescence signal and sensitivity could be increased dramatically. While other flow-FISH methods have been described that utilize PCR-based in situ hybridization to enhance sensitivity, it also increases the cost and the complexity (Patterson et al. 1993; Cho et al. 1996). The use of the LNA flow-FISH method provides a highly generic, cost-effective, and simple technique, which can be easily applied to other viruses and used prior to other more costly and time-consuming techniques.

LNA flow-FISH could be used alone or in tandem with the other methods tested here to provide complementary information on viral infection and viral nucleic acid replication and transcription. This technique is easily applicable to any virus by substituting the LNA probe and is superior to the other methods examined here because of its simplicity. Due to the ability to add additional probes for multiplexing, this technique can be used to develop transcript regulatory networks, which can be used to better understand infectious agents.

\section{MATERIALS AND METHODS}

\section{Cell culture for SV stocks}

BHK-21 cells (American Type Culture Collection) were grown in Dulbecco's modified Eagle's medium (DMEM) supplemented with $10 \%$ fetal bovine serum (FBS) (Cellgro) and 1\% (v/v) penicillin/streptomycin (Sigma) and detached from culture flasks using trypsin-ethylenediamine-tetraacetic acid (EDTA) (Cellgro). Cells were grown in either tissue culture flasks or 6-well plates and incubated at $37^{\circ} \mathrm{C}$ under $5 \% \mathrm{CO}_{2}$ atmosphere.

\section{Sindbis virus stocks}

Recombinant Sindbis virus (SV) (633-EGFP strain) was generously provided by Dr. Diane Griffin (Johns Hopkins University). This virus contains a gene that encodes enhanced green fluorescent protein (EGFP), which is under the control of the same promoter that controls the transcription of the viral subgenomic RNA encoding structural proteins (Scheme 1). The virus seed stock was expanded by infecting BHK cells under serum-free conditions. BHK cells were grown in $\mathrm{T} 150 \mathrm{~cm}^{2}$ tissue culture flasks until $\sim 90 \%$ confluency. The cells were then washed with Dulbecco's PBS and infected with SV at a multiplicity of infection (MOI) of one plaque forming unit (pfu) per cell in $2 \mathrm{~mL}$ of serum-free VP-SFM medium (GIBCO). After $1 \mathrm{~h}$ of incubation at $37^{\circ} \mathrm{C}$, an additional $13 \mathrm{~mL}$ of VP-SFM was added. The cells were allowed to incubate overnight with the virus and were observed the next day for signs of cytopathic effects. The supernatant was collected, centrifuged to remove cellular debris, aliquoted, and stored at $-80^{\circ} \mathrm{C}$.

\section{Quantification of SV supernatant stock by plaque assay}

Each well of a 6 -well plate was seeded with $3 \times 10^{5}$ BHK cells and allowed to form a monolayer overnight. The next day, serial dilutions of the viral supernatant were prepared in 1\% FBS DMEM. An aliquot $(200 \mathrm{uL})$ from each dilution was then incubated with the $\mathrm{BHK}$ monolayer for $1 \mathrm{~h}$ at $37^{\circ} \mathrm{C}$, with rocking every $10 \mathrm{~min}$. After $1 \mathrm{~h}$, the cells were overlayed with warm, melted 1.2\% Bacto agar in water mixed with an equal volume of $2 \mathrm{X}$ MEM (GIBCO). The overlay medium was allowed to solidify at room temperature; then the plates were incubated at $37^{\circ} \mathrm{C}$ for $48 \mathrm{~h}$ to allow for plaque formation. Subsequently, the cells were stained with $0.03 \%$ neutral

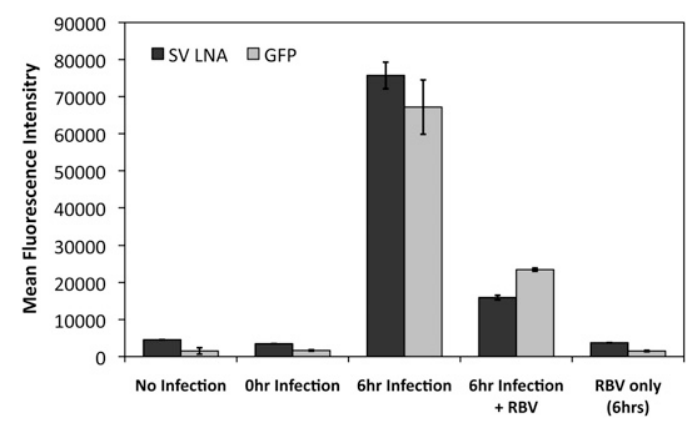

FIGURE 4. Tracking effects of Ribavirin. Bar graph shows the mean fluorescence intensity of SV LNA flow-FISH versus EGFP. 
red in DPBS (Sigma) with 1X MEM. After $2 \mathrm{~h}$ of staining, the stain was removed, and the plaques were observed and counted. The $\mathrm{pfu} / \mathrm{mL}$ in the original supernatant was calculated based on the number of plaques observed and the dilution factor.

\section{LNA probes}

One control oligonucleotide and one specific biotinylated LNAmodified DNA oligonucleotide were used for the quantification of SV RNA. Both were purchased from IDT. The control probe is a nonspecific oligonucleotide (nonspecific LNA) with no complementarity with any cellular nucleic acids and has the sequence $5^{\prime}$-biotin-gtGtaAcaCgtCtaTacGccCa-3' $\left(T_{\mathrm{m}}=75^{\circ} \mathrm{C}\right.$, LNA monomers in uppercase letters). The specific LNA probe (SV LNA), complementary to the SV RNA portion encoding the structural proteins, has the sequence $5^{\prime}$-biotin-tCttCttCccAcaCagCgaTac- $3^{\prime}$ $\left(T_{\mathrm{m}}=76^{\circ} \mathrm{C}\right)$. The $T_{\mathrm{m}}$ 's of the probes were estimated using the Exiqon $T_{\mathrm{m}}$ prediction program (http://na-tm.com) (Tolstrup et al. 2003).

\section{SV infection time course for LNA-flow, EGFP-flow, and qRT-PCR}

BHK cells were seeded into either T75 $\mathrm{cm}^{2}$ flasks or 6-well plates and grown in complete medium (DMEM, supplemented with $10 \%$ FBS and $1 \%(\mathrm{v} / \mathrm{v})$ penicillin/streptomycin) to $\sim 90 \%$ confluency. The monolayer was washed once with PBS, and either $2 \mathrm{~mL}$ (for T75 $\mathrm{cm}^{2}$ flasks) or $0.3 \mathrm{~mL}$ (for six-well plates) of virus (MOI 5:1) in VP-SFM was added. The cells were incubated at $37^{\circ} \mathrm{C}$ with SV for $45 \mathrm{~min}$, with rocking every $10 \mathrm{~min}$. After $45 \mathrm{~min}$, the cells were washed with PBS to remove unbound virus, and either $15 \mathrm{~mL}\left(\mathrm{~T} 75 \mathrm{~cm}^{2}\right.$ ) or $2 \mathrm{~mL}$ (six-well plate) of complete medium was added. At various times, from 0 to $8 \mathrm{~h}$ post-infection (following the 45-min incubation), the cells were washed with PBS and harvested with trypsin-EDTA. 0 Hour infection is defined here as the cell collected immediately following the 45-min viral incubation period. The no infection samples were incubated for the first 45 min with VP-SFM only, and then collected. Complete media was added, and the cells were centrifuged at $2000 \mathrm{rpm}$ for $5 \mathrm{~min}$. The cells were washed with PBS and split into aliquots for qRT-PCR, EGFP, and flow-FISH measurements. Cells for flowFISH were fixed in a solution of $4 \%$ paraformaldehyde (Electron Microscopy Sciences) and 5\% acetic acid in phosphate-buffered saline (PBS) for $10 \mathrm{~min}$ at room temperature. After fixation, the cells were washed twice in PBS and stored at $4^{\circ} \mathrm{C}$ overnight. Cells for EGFP detection were resuspended in PBS and analyzed immediately by flow cytometry for EGFP fluorescence.

Cells for quantitative RT-PCR were pelleted by centrifugation and frozen at $-80^{\circ} \mathrm{C}$ for later RNA extraction. The RNA extraction was performed with an RNeasy Mini Kit (QIAGEN) according to the manufacturers' protocols. The quality of the purified RNA was analyzed by agarose gel electrophoresis and stored at $-80^{\circ} \mathrm{C}$ for use in qRT-PCR.

\section{Viral RNA standard curve}

To produce a SV RNA standard for qRT-PCR, viral RNA was extracted from the viral supernatant stock (see above) using the QIAmp Viral RNA Mini Kit (QIAGEN) according to the manufacturer's protocols. The purified SV RNA standard was then quantified spectrophotometrically.

\section{Quantitative RT-PCR}

Two-step qRT-PCR was performed on the RNA collected from the viral infections time course and on the SV RNA standard from above. First, cDNA was produced using the RETROscript Kit (Ambion/Applied Biosystems) according to the manufacturers' protocols using $1 \mu \mathrm{g}$ of total RNA extracted from the cells at each time post-infection. Then qRT-PCR was performed using a Taqman primer/probe set specially designed for the structural protein-encoding region of the SV RNA (Applied Biosystems). The primer and probe sequences used were: forward primer $5^{\prime}$-gagc cagtgagggtctatgc- $3^{\prime}$, reverse primer $5^{\prime}$-gccatccgtgagggtctc- $3^{\prime}$, and probe $5^{\prime}$-FAM-ctggtgctgactcttg-NFQ- $3^{\prime}$. For the standard curve, six dilutions were measured and the amount of cDNA used from each sample was adjusted so that all sample Ct values fell within the Ct values from the SV RNA standard curve endpoints. The total SV RNA was then calculated from the linear regression curve fit of the SV RNA standard. The data were normalized to the no infection sample according to the following protocol: $\left(x-x_{0}\right) / x_{\max }$, where $x$ is the value from each time point, $x_{0}$ is the value of the no infection sample, and $x_{\max }$ is taken from the time point of maximum gene expression.

\section{Flow-FISH}

The day following fixation, the cells for flow-FISH were permeabilized with $0.1 \mu \mathrm{g} / \mathrm{mL}$ Proteinase $\mathrm{K}$ in TE buffer ( $\mathrm{pH}$ 8.0) for $30 \mathrm{~min}$ at $37^{\circ} \mathrm{C}$. The cells were then washed twice with PBS. A prehybridization step was carried out next under the same conditions as regular hybridization, but without the LNA probe to reduce background fluorescence (Pernthaler and Amann 2004). After prehybridization, a solution of $0.1 \mathrm{X}$ saline-sodium citrate (SSC) buffer was added to reduce viscosity, followed by centrifugation (3000 rcf) and removal of the supernatant. Hybridization was then carried out in $100 \mu \mathrm{L}$ hybridization solution containing 20 pmol SV LNA, $50 \%$ formamide, $10 \%$ dextran sulfate, $50 \mathrm{nM}$ $\mathrm{NaPi}$ (pH 7.0), 2X SSC, and $10 \mu \mathrm{g}$ of sheared salmon sperm DNA (SSSD, Applied Biosystems/Ambion). The sample was denatured for $90 \mathrm{sec}$ at $80^{\circ} \mathrm{C}$ and incubated at $60^{\circ} \mathrm{C}$ for $90 \mathrm{~min}$.

Following hybridization, $0.1 \mathrm{X}$ SSC buffer was added, the cells were centrifuged, and the supernatant removed. The cells were then washed at $65^{\circ} \mathrm{C}$ twice with $50 \%$ formamide and $2 \mathrm{X}$ SSC buffer for $10 \mathrm{~min}$ each, and twice with $0.1 \mathrm{X}$ SSC buffer for $20 \mathrm{~min}$ each. The controls were subjected to the same conditions as above and consisted of either nonspecific LNA or no LNA in place of the SV LNA. Following the washes, the cells were blocked with $1 \mathrm{X}$ in situ hybridization blocking buffer (Vector Laboratories). In separate tubes, the cells and PE-conjugated streptavidin were incubated with the blocking solution for $30 \mathrm{~min}$ at room temperature. Staining was then performed by adding the PE-conjugated streptavidin in blocking solution to the cells. The cells were then washed twice with 0.1X SSC buffer and twice with PBS for $5 \mathrm{~min}$ each at room temperature. The cells were then resuspended in PBS for flow cytometry analysis.

\section{Antiviral studies}

To test the flow-FISH technique for antiviral studies, Ribavirin (Rbv) (Sigma), an antiviral nucleoside analog was used. For these studies, BHK cells were grown in $\mathrm{T} 75 \mathrm{~cm}^{2}$ flasks to $\sim 90 \%$ confluency. For the infected samples, the SV was added to the 
monolayer at an MOI of 5:1 in $2 \mathrm{~mL}$ of VP-SFM for $45 \mathrm{~min}$, with rocking every $15 \mathrm{~min}$. For the uninfected samples, $2 \mathrm{~mL}$ VP-SFM without SV was added. Following the 45-min incubation, the medium was removed from each flask and the cells were washed with PBS. The 45-min infected control cells were harvested and used for flow cytometry (EGFP) and flow-FISH. Complete media $(15 \mathrm{~mL}$ ) with or without $150 \mu \mathrm{g} / \mathrm{mL}$ Rbv was added to the other flasks and allowed to incubate at $37^{\circ} \mathrm{C}$ for $6 \mathrm{~h}$.

\section{Flow cytometry and sata nalysis}

Flow cytometry analysis was performed using an Accuri C6 flow cytometer equipped with a 488-nm and 635-nm laser and standard emission filters for FITC, PE, PI, and APC. For each sample, $2 \times 10^{4}$ events were collected in a gate corresponding to the cell population.

In order to calculate the number of cells positive for virus, a gate was created to encompass the population of cells on a scatter plot of SSC versus PE intensity (FL-2) that were negative for virus (based on the no infection sample). Cells showing fluorescence intensities greater than this population were taken to be positive for SV.

\section{ACKNOWLEDGMENTS}

This work was supported in part by the Office of Naval Research and in part by JSTO-CBD/DTRA Project Number 4.10004.08. NRL.

Received November 24, 2009; accepted May 20, 2010.

\section{REFERENCES}

Baerlocher GM, Mak J, Tien T, Lansdorp PM. 2002. Telomere length measurement by fluorescence in situ hybridization and flow cytometry. Cytometry 47: 89-99.

Bauman JGJ, Bayer JA, Dekken Hv. 1990. Fluorescent in situ hybridization to detect cellular RNA by flow cytometry and confocal microscopy. J Microsc 157: 73-81.

Bayer JA, Bauman JGJ. 1990. Flow cytometric detection of $\beta$-globin mRNA in murin haemopoietic tissues using fluorescent in situ hybridization. Cytometry 11: 132-143.

Belloc F, Durrieu F. 1994. Detection of mRNA species by flow cytometry. Methods Cell Biol 42: 59-69.

Belloc F, Lacombe F, Cumain P, Mergny JL, Lopez F, Bernard P, Reiffers J, Boisseau MR. 1993. Flow cytometric estimation of poly $(\mathrm{A})^{+}$RNA by fluorescent in situ hybridization. Cytometry 14: 339-343.

Bentzen EL, House F, Utley TJ, Crowe JE, Wrigth DW. 2005. Progression of respiratory syncytial virus infection monitored by fluorescent quantum dot probes. Nano Lett 5: 591-595.

Borzì RM, Piacentini A, Monaco MCG, Lisignoli G, Degrassi A, Cattini L, Santi S, Facchini A. 1996. A fluorescent in situ hybridization method in flow cytometry to detect HIV-1 specific RNA. J Immunol Methods 193: 167-176.

Braasch DA, Corey DR. 2001. Locked nucleic acid (LNA): Fine-tuning the recognition of DNA and RNA. Chem Biol 8: 1-7.

Cheng EH-Y, Levine B, Boise LH, Thompson CB, Hardwick JM. 1996. Bax-independent inhibition of apoptosis by $\mathrm{Bcl}-\mathrm{x}_{\mathrm{L}}$. Nature 379: 555-556.

Cho SW, Hwang SG, Han DC, Jin SY, Lee MS, Shim CS, Lee DW, Lee HB. 1996. In situ detection of hepatitis $\mathrm{C}$ virus RNA in liver tissue using a digoxigenin-labeled probe created during a polymerase chain reaction. J Med Virol 48: 227-233.
Crouch J, Leitenberg D, Smith BR, Howe JG. 1997. Epstein-Barr virus suspension cell assay using in situ hybridization and flow cytometry. Cytometry 29: 50-57.

Dawson GJ. 2007. HCV core antigen and combination (antigen/ antibody) assays for the detection of early seroconversion. $J$ Med Virol 79: S54-S58.

Delehanty JB, Bongard JE, Thach DC, Knight A, Hickey TE, Chang EL. 2008. Antiviral properties of cobalt (III)-complexes. Bioorg Med Chem 16: 830-837.

Elayadi AN, Braasch DA, Corey DR. 2002. Implication of high-affinity hybridization by locked nucleic acid oligomers for inhibition of human telomerase. Biochemistry 41: 9973-9981.

Fox JD. 2007. Nucleic acid amplification tests for detection of respiratory viruses. J Clin Virol (Suppl. 1) 40: S15-S23.

Just T, Burgwalk H, Brow MK. 1998. Flow cytometric detection of EBV (EBER snRNA) using peptide nucleic acid probes. $J$ Virol Methods 73: 163-174.

Koshkin AA, Singh SK, Nielsen P, Rajwanshi VK, Kumar R, Meldgaard M, Olsen CE, Wengel J. 1998. LNA (locked nucleic acids): Synthesis of the adenine, cytosine, guanine, 5-methylcytosine, thymine and uracil bicyclonucleoside monomers, oligomerisation, and unprecedented nucleic acid recognition. Tetrahedron 54: 36073630.

Kubota K, Ohashi A, Imachi H, Harada H. 2006. Improved in situ hybridization efficiency with locked-nucleic-acid-incorporated DNA probes. Appl Environ Microbiol 72: 5311-5317.

Kuhn RJ. 2007. Togaviridae: The viruses and their replication. In Fields virology (ed. DM Knipe, PM Howley), 5th ed., Lippincott Williams \& Wilkins, Philadelphia, PA.

Leski TA, Lin B, Malanoski AP, Wang Z, Long NC, Meador CE, Barrows B, Ibrahim S, Hardick JP, Aitichou M, et al. 2009. Testing and validation of high density resequencing microarray for broad range biothreat agents detection. PLoS ONE 4: e6569. doi: 10.1371/ journal.pone.0006569.

Lizard G, Chignol MC, Chardonnet Y, Souchier C, Bordes M, Schmitt D, Revillard JP. 1993. Detection of human papillomavirus and confocal laser scanning microscopy. J Immunol Methods 157: 3138.

Los M. 2006. Virus detection today. In modern bacteriophage biology and biotechnology (ed. G Węgrzyn), pp. 131-152. Research Signpost, Kerala, India.

Malinoski F, Stollar V. 1981. Inhibition of Sindbis virus replication by ribavirin: Influence of cultural conditions and of the host cell phenotype. Antiviral Res 1: 287-299.

Mosleh N, Dadras H, Mohammadi A. 2009. Molecular quantitation of H9N2 avian influenza virus in various organs of broiler chickens using TaqMan real-time PCR. J Mol Genet Med 3: 152157.

Mulrooney PM, Michalak TI. 2003. Quantitative detection of hepadnavirus-infected lymphoid cells by in situ PCR combined with flow cytometry: Implications for the study of occult virus persistence. J Virol 77: 970-979.

Narimatsu R, Patterson BK. 2005. High-throughput cervical cancer screening using intracellular human papillomavirus E6 and E7 mRNA quantification by flow cytometry. Anat Pathol 123: 716723.

Obika S, Nanbu D, Hari Y, Morio K-I, In Y, Ishida T, Imanishi T. 1997. Synthesis of 2'-O, 4'-C-methyleneuridine and -cytidine: Novel bicyclic nucleosides having a fixed $\mathrm{C}^{\prime}$ - endo sugar puckering. Tetrahedron Lett 38: 8735-8738.

Patterson BK, Till MT, Otto P, Goolsby C, Furtado MR, McBride LJ, Wolinsky SM. 1993. Detection of HIV-1 DNA and messenger RNA in individual cells by PCR-driven in situ hybridization and flow cytometry. Science 260: 976-979.

Pernthaler A, Amann R. 2004. Simultaneous fluorescence in situ hybridization of mRNA and rRNA in environmental bacteria. Appl Environ Microbiol 70: 5426-5433.

Polage CR, Petti CA. 2009. Clinical virology manual. American Society for Microbiology, Washington, DC. 
Rabenau HF, Kessler HH, Kortenbusch M, Steinhorst A, Raggam RB, Berger A. 2007. Verification and validation of diagnostic laboratory tests in clinical virology. J Clin Virol 40: 93-98.

Robertson KL, Thach DC. 2009. LNA flow-FISH: A flow cytometryfluorescence in situ hybridization method to detect messenger RNA using locked nucleic acid probes. Anal Biochem 390: 109-114.

Sanz MA, Castelló A, Carrasco L. 2007. Viral translation is coupled to transcription in Sindbis virus-infected cells. J Virol 81: 7061-7068.

Silahtaroglu A, Pfundheller H, Koshkin AA, Tommerup N, Kauppinen S. 2004. LNA-modified oligonucleotides are highly efficient as FISH probes. Cytogenet Genome Res 107: 32-37.

Silahtaroglu A, Tommerup N, Vissing H. 2003. FISHing with locked nucleic acids (LNA): Evaluation of different LNA/DNA mixmers. Mol Cell Probes 17: 165-169.

Steininger C, Kundi M, Aberle SW, Aberle JH, Popow-Kraupp T. 2002. Effectiveness of reverse-transcription-PCR, virus isolation, and enzyme-linked immunosorbent assay for diagnosis of influenza A virus infection in different age groups. J Clin Microbiol 40: 2051-2056.

Stowe RP, Cubbage ML, Sams CF, Pierson DL, Barrett ADT. 1998. Detection and quantification of Epstein-Barr virus EBER1 in EBV- infected cells by fluorescent in situ hybridization and flow cytometry. J Virol Methods 75: 83-91.

Taneja KL. 1998. Localization of trinucleotide repeat sequences in myotonic dystrophy cells using a single fluorochrome-labeled PNA probe. Biotechniques 24: 472-475.

Thach DC, Stenger DA. 2003. Effects of collagen matrix on Sindbis virus infection of BHK cells. J Virol Methods 109: 153-160.

Thomsen R, Nielsen PS, Jensen TH. 2005. Dramatically improved RNA in situ hybridization signals using LNA-modified probes. RNA 11: 1745-1748.

Tolstrup N, Nielsen PS, Kolberg JG, Frankel AM, Vissing H, Kauppinen S. 2003. OligoDesign: Optimal design of LNA (locked nucleic acid) oligonucleotide capture probes for gene expression profiling. Nucleic Acids Res 31: 3758-3762.

Vermeulen CFW, Jordanova ES, Szuhai K, Kolkman-Uljee S, Vrede MA, Peters AAW, Schuuring E, Fleuren GJ. 2007. Physical status of multiple human papillomavirus genotypes in flow-sorted cervical cancer cells. Cancer Genet Cytogenet 175: 132-137.

Wang D, Coscoy L, Zylberberg M, Avila PC, Boushey HA, Ganem D, DeRisi JL. 2002. Microarray-based detection and genotyping of viral pathogens. Proc Natl Acad Sci 99: 15687-15692. 

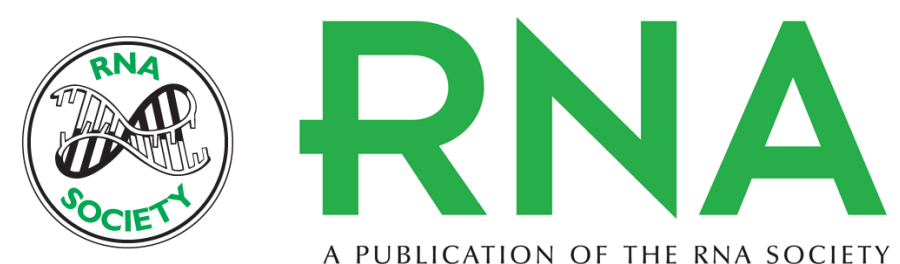

A PUBLICATION OF THE RNA SOCIETY

\section{Monitoring viral RNA in infected cells with LNA flow-FISH}

Kelly L. Robertson, Anne Brooks Verhoeven, Dzung C. Thach, et al.

RNA 2010 16: 1679-1685 originally published online June 28, 2010

Access the most recent version at doi:10.1261/rna.2016410

\section{References This article cites 40 articles, 8 of which can be accessed free at: http://rnajournal.cshlp.org/content/16/8/1679.full.html\#ref-list-1}

Open Access Freely available online through the RNA Open Access option.

License Freely available online through the RNA Open Access option.

Email Alerting Receive free email alerts when new articles cite this article - sign up in the box at the Service top right corner of the article or click here. 